\title{
FABRICATION OF HYDROPHILIC AND STRONG PET-BASED MEMBRANE FROM WASTED PLASTIC BOTTLE
}

\author{
S. Mulyati ${ }^{*}$, M. A. Armando ${ }^{1}$, H. Mawardi ${ }^{1}$, A. Fahrina ${ }^{1}$, \\ N. Malahayati ${ }^{1}$, and Syawaliah ${ }^{2}$ \\ ${ }^{1}$ Department of Chemical Engineering, Syiah Kuala University, 23111, Banda Aceh, Indonesia \\ ${ }^{2}$ Doctoral School of Engineering Science, Syiah Kuala University, 23111, \\ Banda Aceh, Indonesia \\ *E-mail : sri.mulyati@unsyiah.ac.id
}

\begin{abstract}
In this study, the wasted plastic bottle has been recycled as a polymeric material to fabricate PET-based membrane by adding cellulose acetate and silica to enhance the performance. Cellulose acetate was added as a sub-polymer to increase mechanical property of the PET membrane. Meanwhile, silica which derived from rice husk was used as a membrane pore-forming agent. PET/CA/SiO ${ }_{2}$ membrane was fabricated using the phase inversion technique via thermal induced phase separation method. The permeation and selectivity performances of the prepared membrane were tested. Other fundamental characterizations of the membrane such as morphological, functional groups, tensile strength, contact angle, roughness, and thickness were also analyzed. From the result, it was found that the addition of silica successfully improved the hydrophilicity as well as the filtration performance of the membrane.

Keywords: Polyethylene terephthalate (PET), Cellulose acetate (CA), biosilica, green technology, waste plastic bottle, silica oxide, rice husk
\end{abstract}

(c) RASĀYAN. All rights reserved

\section{INTRODUCTION}

Membrane technology has been leading a strategic role in the sustainable development of many industries. Membrane technology is greatly preferred and applied in various sectors like in the medical field, bio-separation, bio-refinery, food and beverage industry, megaproject water treatment plant, water reclamation with membrane bioreactor, energy generator, and gas separation ${ }^{1}$ due to many merits it offers such as low energy consumption, ease of scaling-up, can be combined with other separation processes, and needless of additional chemicals during the filtration process. ${ }^{2}$

The separation capability of a membrane in its application is mostly influenced by membrane composition. Membrane base-materials are generally sourced from organic compounds such as polymers. Some of the frequently used polymers as membrane material are polyethersulfone (PES), cellulose acetate (CA), polysulfone (PSf), polyvinylidene fluoride (PVDF), and polyethylene terephthalate (PET). The characteristics of each of these polymers are different which will accordingly affect the characteristics of the fabricated membranes, such as hydrophilicity, flexibility, and fouling resistance, that will also affect the operation performance. ${ }^{3}$

Commercial polymers certainly have an expensive price which increases membrane production cost. Therefore, it is necessary to create a membrane with an appropriate composition to produce an economic membrane with superior characteristics. One of the ways to reduce the consumption of commercial polymers and membrane manufacturing costs is by utilizing polymer-based waste materials.

Advanced technology in food and beverage sectors currently encourage the use of polyethylene terephthalate (PET) as plastic packaging. PET has a strong and durable structure, as well as excellent stability at high temperatures. These properties lead PET difficult to degrade in the environment. ${ }^{4}$ The continuous use of PET leads to the increment of a waste of PET-based plastic bottle and cause

Rasayan J. Chem., 11(4), 1609-1617(2018)

http://dx.doi.org/10.31788/RJC.2018.1144047

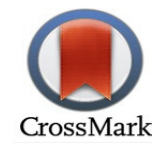


environmental pollution. However, plastic bottle can be potentially re-used by utilizing the PET as the main material of the polymeric membrane. Moreover, the advantages of this PET waste-based membrane are not only able to reduce membrane production costs, but also support green technology that minimizes environmental pollution.

The manufacture of PET membrane from the waste plastic bottle had previously been investigated by Rajesh and Murthy. ${ }^{5}$ The resulting membrane had weak mechanical and hydrophilicity properties. Therefore, an additional modification is needed to improve its characteristics, for instance by combining it with other polymeric material to produce composite membrane. ${ }^{6-8}$ Arahman ${ }^{2}$ continued the investigation by adding PVP as an additive to the waste-based PET membrane. The formed membrane showed better resistance than the PET membrane without additive. It can be concluded that PET from plastic bottles cannot be utilized alone to fabricate the self-standing PET membrane, it needs to be combined with other polymers as additives.

In this study cellulose acetate (CA) polymer used as a copolymer to facilitate the formation of the strong PET-based membrane. It was reported that additional CA on the membrane can greatly enhance the mechanical strength ${ }^{9,10}$, as well as the hydrophilicity ${ }^{11}$ of the membrane. For further improvement, natural silica derived from rice husk used to enhance the pore properties and hydrophilicity of PET/CA membrane. The silica addition to the membrane can improve membrane hydrophilicity and prevent fouling or plugging in membrane pores by foulant particles during the separation process. ${ }^{12}$ Lin $^{13}$ used silica stöber as a nanofiller on the PES membrane, the resulting membrane showed an increased flux of humic acid filtration. Therefore, silica is chosen as a suitable material to fix the hydrophobic properties of the PET membrane. The silica used in this work was produced by isolation from rice husks waste. The concentration of rice husk nano-silica used in this study was varied from $0,0,5$ and $1 \%$. PET membrane was prepared by thermal induced phase separation (TIPS) technique.

\section{EXPERIMENTAL}

\section{Preparation and Characterization of Rice Husk Biosilica}

Rice husk was sourced from rice mills in the vicinity of Banda Aceh city. The isolation of silica from rice husk was done by extraction method using a $\mathrm{KOH}$ solution. Rice husk was dissolved in $10 \%$ of $\mathrm{KOH}$ at boiling temperature for 1 hour. $\mathrm{HCl} 10 \%$ was added to the solution to precipitate silica. Centrifugation process was done at $2800 \mathrm{rpm}$ for 30 minutes for silica settling acceleration and continued by drying. Silica particle size was reduced to nano-sized by using ball mills.

\section{Preparation of Membrane}

The PET polymer used as a membrane material in this study was obtained from plastic bottles waste. The used plastic bottles were cleaned up, dried and followed by cutting to obtain smaller material. Next, phenol was liquefied at $40^{\circ} \mathrm{C}$. The PET as the main polymer, CA as a copolymer, and silica as an additive were altogether dissolved into phenol solvent at a temperature of $80^{\circ} \mathrm{C}$ with stirring until homogeneity is obtained. The silica was added with varying concentrations of $0,0,5$ and $1 \%$, in which the concentration was based on the concentration of PET polymer. The casting solution was poured on a glass plate and cast by using a casting with the gap set at $700 \mu \mathrm{m}$. The casting film was evaporated for 15 seconds and then dipped into a coagulation bath containing water-ethanol with a ratio of 15:1 as a nonsolvent. The formed membrane sheet was annealed by heating at $70^{\circ} \mathrm{C}$ for 15 minutes. Subsequently, the fabricated membrane was stored in distilled water for further use.

\section{Characterization of Membrane}

Fourier-Transform Infrared Spectroscopy Attenuated Total Reflectance Instrument (FTIR-ATR) (Thermo Scientific iD5 ATR-Nicolet iS5 FTIR Spectrophotometer, Japan) was employed to analyze the chemically functional groups of fabricated membranes. All samples were freeze-dried before analysis.The roughness characteristic of membrane surface was evaluated using Atomic Force Microscopy (AFM, SPI300N, Hitachi, Ltd, Japan). The data is presented in form of RMS (Root Mean Square) which obtained by calculation using Eqn.-1. ${ }^{14}$ 
RASĀYAN J. Chem.

Vol. 11 | No. 4 |1609 - 1617| October - December | 2018

$\operatorname{RMS}=\sqrt{\frac{1}{n} \sum_{i=1}^{n} z i^{2}}$

Where $\mathrm{z}$ denotes the deviation depth of the membrane, and $\mathrm{n}$ symbolizes the number on the discrete deviation of the membrane.

Contact angle meter instrument (Drop Master 300, Kyowa Interface Science Co., Japan) was used to measure membrane hydrophilicity. Prior to measurement, the samples were dried in a freeze dryer (FD100, Eyela, Japan) to assure no water content in the samples. The measurement was conducted by dropping $1 \mu \mathrm{L}$ of Milli-Q water on the membrane surface. The angle of water droplet formed was then determined.

The mechanical characteristic of membranes was measured by using a Tensile Meter (Hungta Instrument Co. Ltd, Type HT-8503), the procedure was adapting the ASTM D638 standard at a velocity of 20 $\mathrm{mm} / \mathrm{min}$ and $1 \mathrm{~cm}$ clamp distance.

\section{Evaluation of Permeation and Separation Performance}

The filtration experiment was conducted using a driven dead-end filtration module utilizing the pressure from nitrogen gas as a driving force (Fig.-1). The operating condition was set at 2, 2.5, 3 and 3.5 bar. Filtration was performed for 0.5 hours and permeate was accommodated and measured every 5 minutes. Filtration process was carried out for pure water permeability and humic acid as an organic matter foulant model. The volume of collected permeate was weighed and the permeability was calculated by Eqn.- 2 .

$L p=\frac{J}{\Delta P}$

Lp represents the coefficient of permeability ( $\mathrm{L} / \mathrm{m}^{2}$.hour.bar), $\mathrm{J}$ for flux $\left(\mathrm{L} / \mathrm{m}^{2}\right.$.hour), $\Delta \mathrm{P}$ is trans membrane pressure (bar). 10 ppm humic acid solution was utilized for selectivity test. The ability of the membrane to reject humic acid was determined by Eqn.-3.

$\% R=\left(1-\frac{C_{p}}{C_{f}}\right) \times 100$

Where $\mathrm{R}$ is the coefficient of rejection (\%), $\mathrm{Cp}$ is concentration of filtrated permeate and $\mathrm{Cf}$ is concentration of feed solution.

\section{RESULTS AND DISCUSSION}

In order to confirm the successful incorporation of the additive into the membrane system, chemical composition analysis was conducted by means of ATR-FTIR instrument. Infrared spectroscopy analysis is a simple and rapid technique for the identification of functional groups in organic compounds. ${ }^{15}$ The spectra results for pure and silica modified PET membrane are shown in Fig.-2. It is seen that the PET/CA membrane with and without silica blending contain the $\mathrm{C}-\mathrm{O}$ group at a wavenumber of $1100 \mathrm{~cm}^{-1}$. The aromatic alcohol group emerges at a wavenumber of $1510 \mathrm{~cm}^{-1}$. In addition, the $\mathrm{C}=\mathrm{O}$ and $\mathrm{C}-\mathrm{H}$ groups are seen at a wavenumber of $1755 \mathrm{~cm}^{-1}$ and $2950 \mathrm{~cm}^{-1}$, respectively. All of these peaks are attributed to the vibrations of the atoms in the material containing polyethylene terephthalate (PET). For the silica-blended membranes, the appearance of little peaks at a wavenumber of $950 \mathrm{~cm}^{-1}$ and $1051 \mathrm{~cm}^{-1}$ indicates the presence of $\mathrm{Si}-\mathrm{OH}$ and $\mathrm{Si}-\mathrm{O}-\mathrm{Si}$ from nano silica additive. ${ }^{16,17}$ The intensity of emergence peaks cannot obviously be observed as the modification was performed by blending technique whereas the IR analysis was performed on the membrane surface. Moreover, most of the silica moieties probably have been leached out during phase inversion.

To further check the effect of silica of different concentrations on the membrane surface morphology, atomic force microscopy (AFM) investigation was done and results are presented in Figure 3. Root Mean Roughness (RMS) membrane PET/CA without silica is $1,29 \mathrm{~nm}$ indicating that the membrane has a very smooth surface without the addition of silica. The smoothness of the membrane surface usually indicates that the membrane is having a dense or less porous surface. ${ }^{18}$ Blending $0.5 \%$ of silica into the membrane increased the roughness value to $6,89 \mathrm{~nm}$. It is presumably because silica serves as a pore-forming agent. Silica has a great affinity towards water and causes leach out during precipitation process which affects 
RASĀYAN J. Chem.

Vol. 11 | No. 4 |1609 - 1617| October - December | 2018

pores formation and distribution on the surface of the fabricated membrane. ${ }^{13,19}$ The formation of pores causes the membrane to have a rough surface layer. However, when the concentration of silica increased to $1 \%$, the roughness of the membrane slightly lowered to $6.25 \mathrm{~nm}$. This could be because when too much amount of silica blended, the casting solution becomes saturated and its function as a pore agent does not work properly and the fabricated membrane has fewer pores formation. As the result, membrane $\mathrm{PET} / \mathrm{CA} / \mathrm{SiO}_{2}$ have less RMS value $(6,25 \mathrm{~nm})$ in comparison to $\mathrm{PET} / \mathrm{CA} / \mathrm{SiO}_{2} 0,5 \%$. However, the further detailed study is necessary to clarify the reason for the decrease in surface roughness. A similar result was also reported by Woo and research team ${ }^{20}$ in their recently published work.

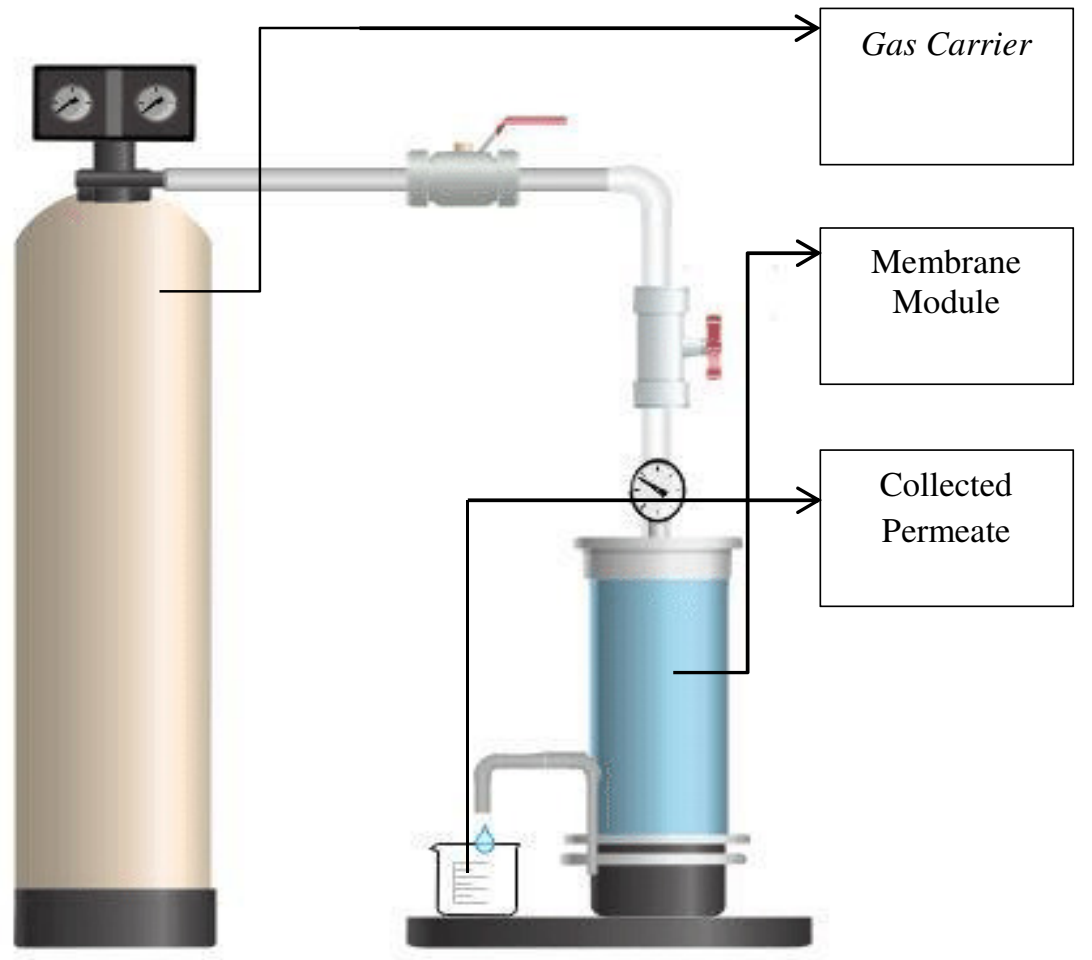

Fig.-1: Scheme of the Experimental Set-up for Filtration Test
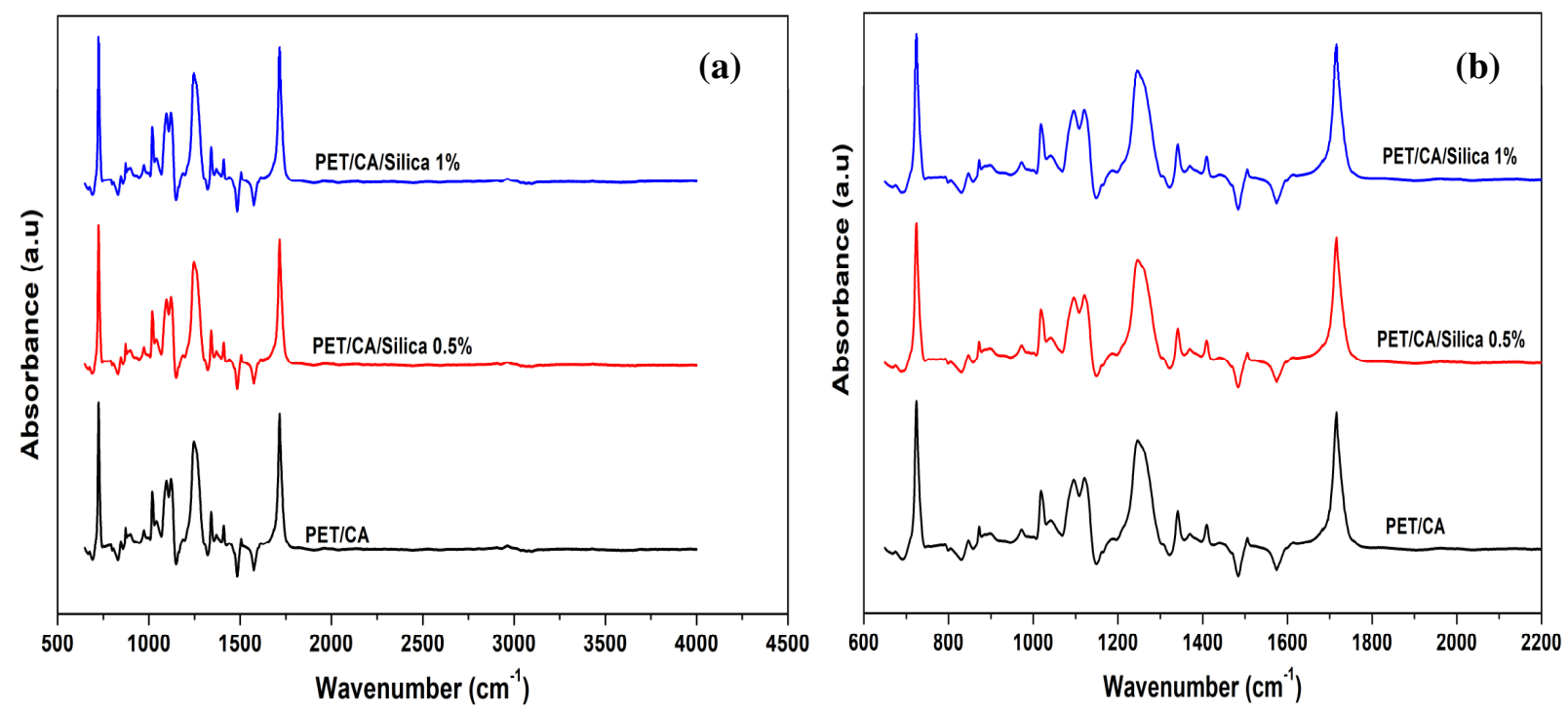

Fig.-2: Spectra Analysis of Membrane with Various Content of $\mathrm{SiO}_{2}$. (a) Full Spectrum range (b) Magnification on Spectrum Range of 600 to $2200 \mathrm{~cm}^{-1}$

The hydrophilicity of prepared membranes with various content of $\mathrm{SiO}_{2}$ was also investigated by water contact angle as presented in Figure 4. PET is one of the petroleum derivative polymers which has 
superhydrophobic properties. Although PET polymer is blended with CA, fabricated membrane still has a considerably high contact angle, which is $98,4^{\circ}$. The contact angle shows a remarkable decrease with the increased loading of silica. For example, by adding only $0.5 \%$ of silica, the contact angle of PET/CA membrane dropped significantly to $85,71^{\circ}$ which means the membran becomes more hydrophilic after silica addition. However, by increasing the silica loading to $1 \%$ (named as PET/CA/SiO $/ 1 \%$ membrane), the contact angle of the membrane has a slim increase to $89,71^{\circ}$. This phenomenon can be explained as follows. Addition of silica improved the hydrophilicity of the membrane surface by its high bonding reactivity with water. However, the contact angle of a porous materia is not only based on this but also other surface chemistry parameters such as, roughness, porosity and pore size. ${ }^{21}$

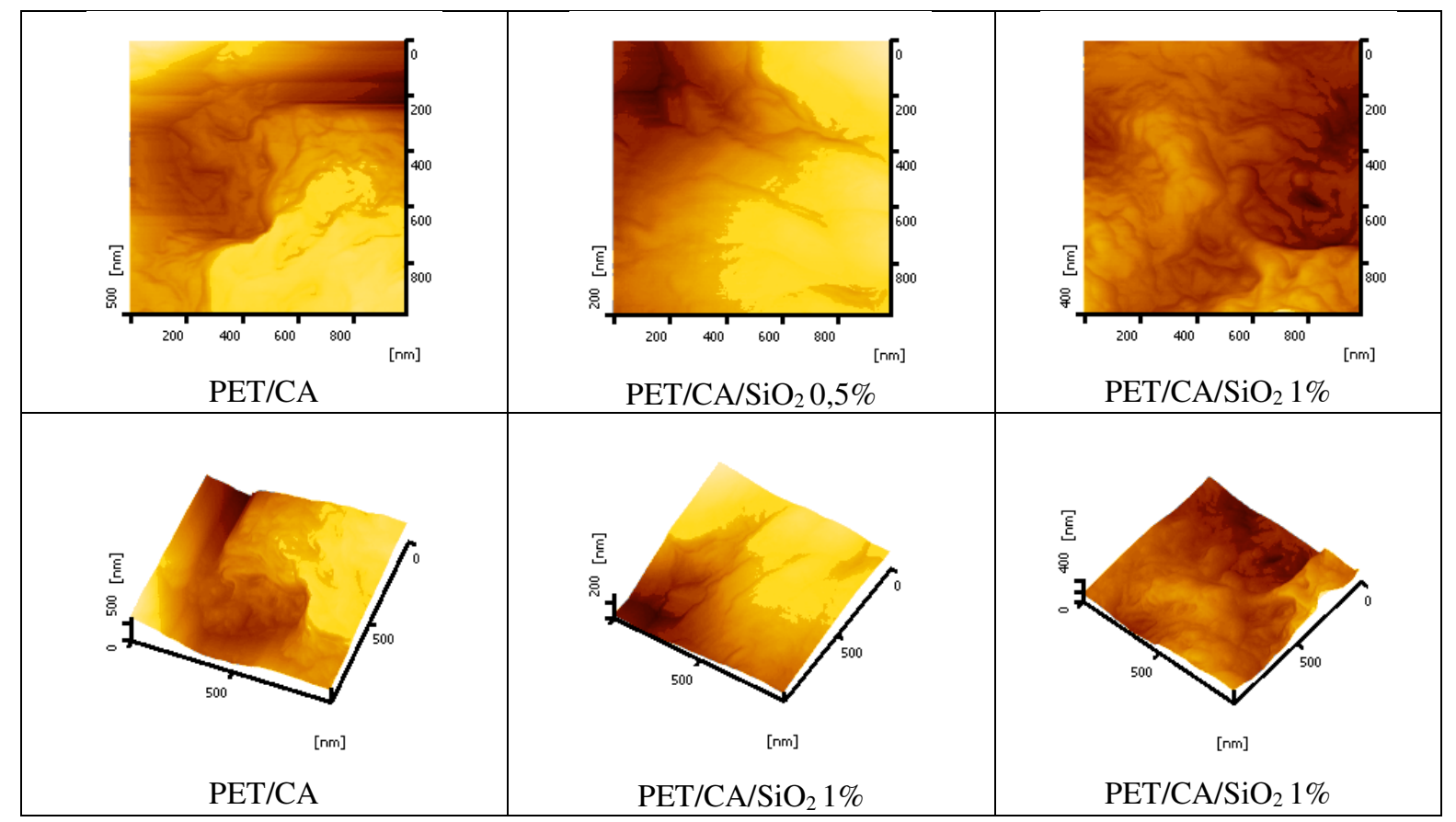

Fig.-3: AFM imaging of membrane surface. Two-dimensional images (top). Three-dimensional images (bottom).

It is a common knowledge that membrane with the more porous surface will have a lower contact angle. As previously discussed in AFM results, the membrane with $0.5 \%$ addition of silica is seemed to have a more porous surface. Meanwhile, adding $1 \%$ of silica makes the membrane to have a less rough surface which indicates the lack presence of pores. So, it is understandable why PET/CA/SiO $1 \%$ possess a higher contact angle in comparison to that of with $0.5 \%$ silica. It is because, for the $0.5 \%$ silica addition membrane, the hydrophilicity increment is helped by the hydrophilic nature of silica and also the pore structures of the membrane. However, for the membrane with $1 \%$ silica, the surface pores seem to be denser hence the contact angle increased a little. In addition, it is reported in another literature that at higher silica loading, it will cause the membrane to have a lower surface energy which leads to higher contact angle value. ${ }^{22}$ Nevertheless, it can be concluded that the nano silica from rice husk can increase the hydrophilicity of superhydrophobic PET-based membrane. Hydrophilicity is an important parameter for a membrane because it improves the interaction of membrane surface with water molecule which will affect the water permeability performance which also simultaneously decreases the interaction with foulant which leads to the excellent antifouling property.

Membrane ability to allow water to pass through and retain the other certain components is referred to as permeability. Membrane permeability can be determined by measuring a pure water flux. Pure water flux is one of the most vital and basic properties of the membrane, because it represents pore properties and morphology of the membrane. ${ }^{19}$ The pure water flux and coefficient of permeability has a linear correlation and results from the experiment of this research is shown in Fig.-5. 
RASĀYAN $J$. Chem.

Vol. 11 | No. 4 |1609 - 1617| October - December | 2018

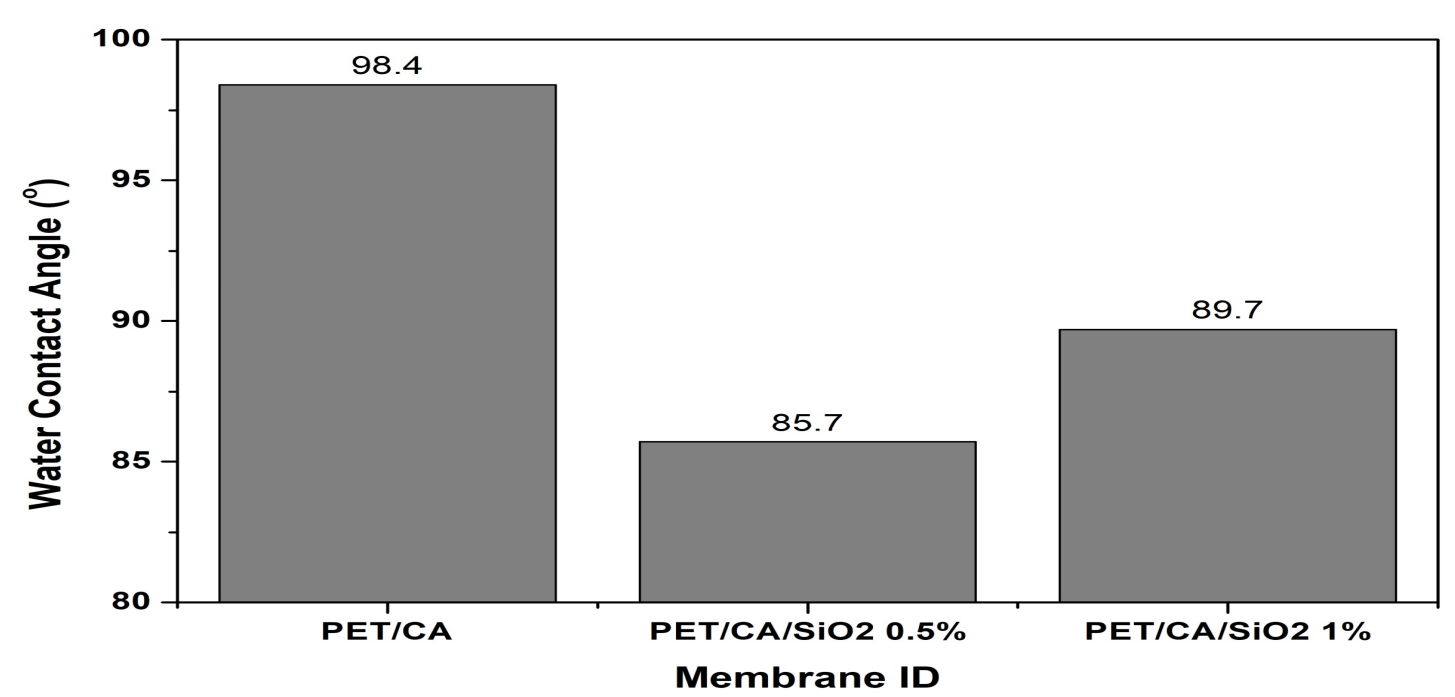

Fig.-4: Water Contact Angle of Fabricated Membranes with Various Content of $\mathrm{SiO}_{2}$.

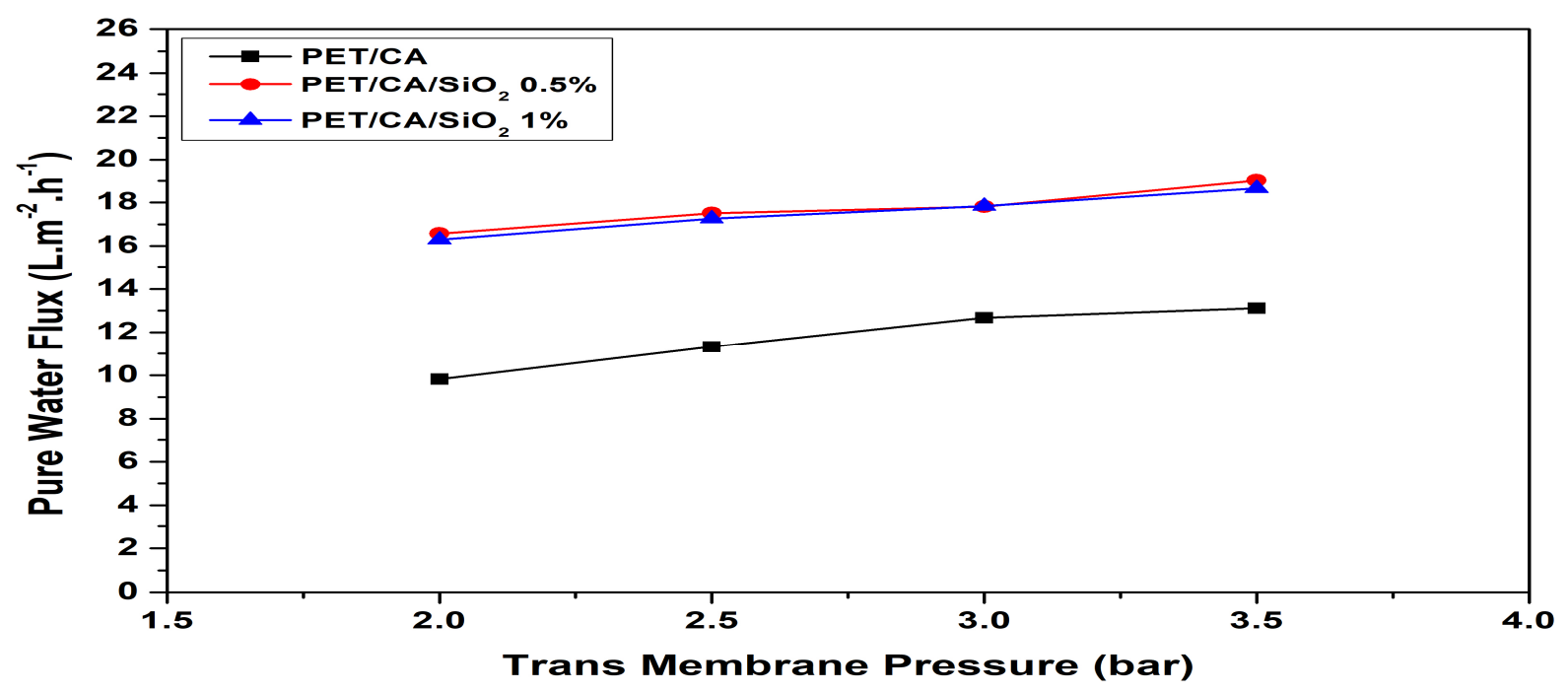

Fig.-5: Pure Water Flux of prepared Membranes at a Different Trans Membrane Pressure

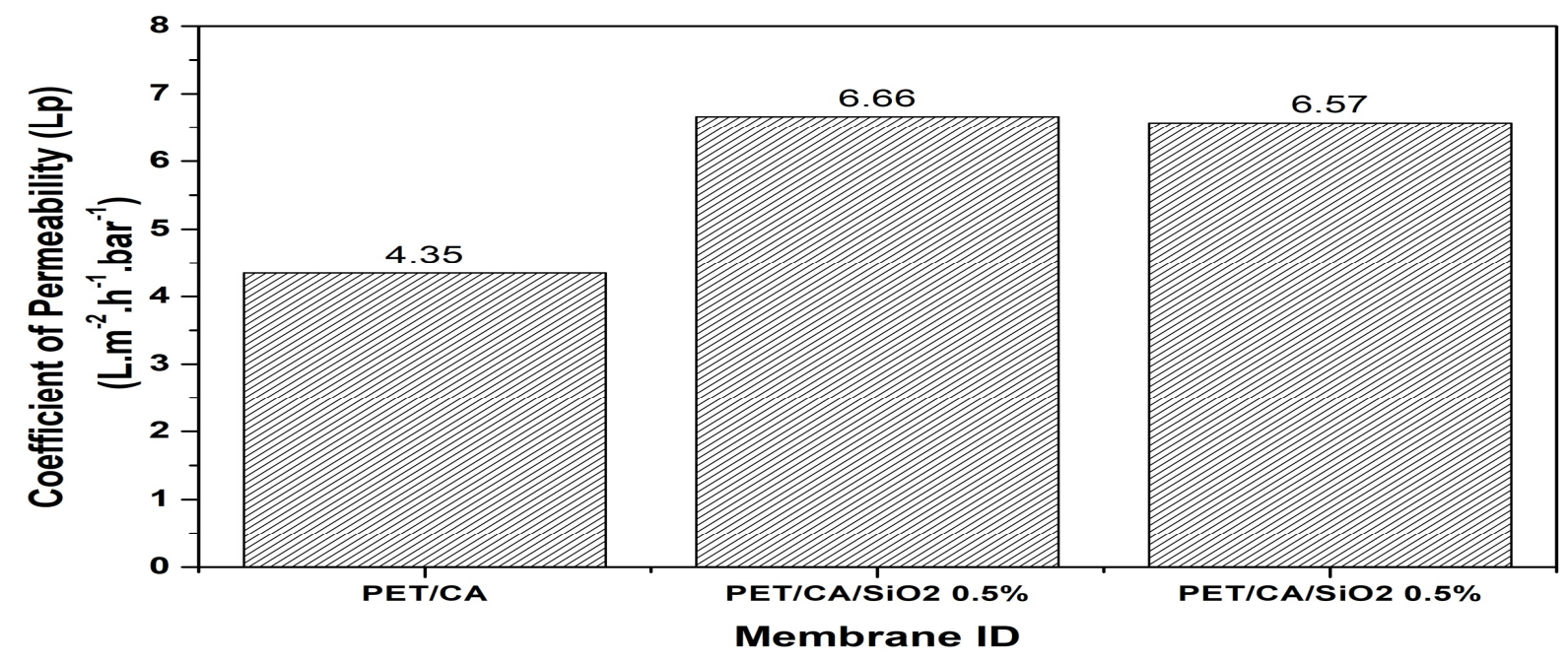

Fig.-6: The Permeability of the Membrane with Various Content of Silica 
The filtration experiment was conducted by utilizing pressure as a driving force, therefore pure water flux was found to be larger when trans membrane pressure (TMP) increased. As shown in Fig.-6, the coefficient of permeability of the membrane without silica was only 4,35 L.m ${ }^{-2}$.hour ${ }^{-1} \cdot$ bar $^{-1}$, then increased very slightly to 6,67 and $6,57 \mathrm{~L} \cdot \mathrm{m}^{-2} \cdot \mathrm{hour}^{-1} \cdot \mathrm{bar}^{-1}$ on $\mathrm{PET} / \mathrm{CA} / \mathrm{SiO}_{2} \quad 0,5 \%$ and $\mathrm{PET} / \mathrm{CA} / \mathrm{SiO}_{2} 1 \%$, respectively. The enhancement of water flux on the silica-blended membranes is attributed to the hydrophilic nature of membrane ${ }^{19}$ which supported by the results of contact angle analysis. Hydrophilic membrane surface causes the water molecule has a greater chance to be adsorbed to the membrane surface. ${ }^{23}$ The addition of silica also acts as a pore agent which improves the distribution of pores on the membrane surface. ${ }^{12,13}$ However, pure water flux decreased in $1 \%$ silica addition. This problem is presumably due to silica as an additive does not work properly at higher concentration, as have been discussed previously.

To evaluate the separation performance of fabricated membranes, solute rejection experiment of all fabricated PET membranes was carried out by using humic acid solution with a concentration of $10 \mathrm{ppm}$ at operating pressure of 3 bar. The concentration of permeate was measured using a UV-Vis Spectrometer. The result is shown in Fig.-7.

According to Fig.-7, the capability of membranes to reject humic acid increases significantly on membranes modified by silica. The comparison of humic acid rejection by PET/CA and PET/CA/SiO 2 $1 \%$ membrane increased from $58 \%$ to $61 \%$. The addition of silica improved the hydrophilic of the membrane surface which advantageous in preventing the humic acid from being adsorbed on the surface of the membrane due to low bonding interactions. Zhao et. $\mathrm{al}^{23}$ also reported that the hydrophilic layer coating composed of silica particles acts as a barrier to increase the rejection of humic acid.

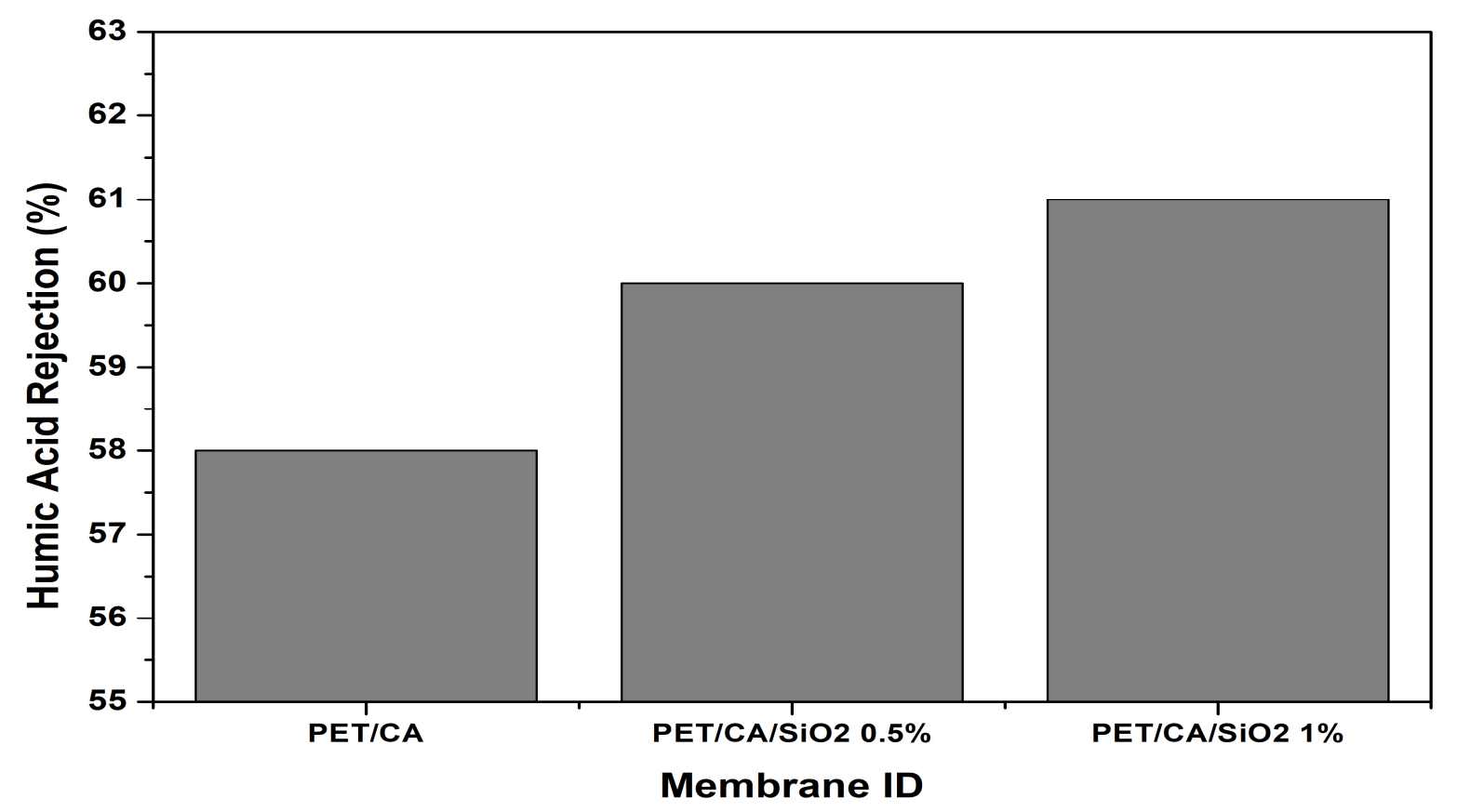

Fig.-7: Humic Acid Rejection by PET Membranes with Various Content of Silica

Mechanical properties measurement indicates membrane capability to resist stream pressure during filtration. The mechanical properties of the fabricated membrane were investigated in terms of tensile stress as presented in Fig.-8. Arahman et $\mathrm{al}^{2}$ and Rajesh ${ }^{5}$ reported that membrane PET from bottle plastic has weak mechanical properties.

However, based on results in Fig.-8, our PET/CA membrane showcases the highest mechanical strength which is $32,17 \mathrm{kgf} / \mathrm{mm}^{2}$. It is proven that CA as a sub-polymer can increase mechanical properties properly. On the contrary, the addition of silica weakens the membrane. Presumably, because the addition of silica leads to increased membrane porosity and formation of macrovoid in the bulk structure which 
consequently decreases the mechanical property of the membrane. The tensile at break data of membrane with silica loading of $0,5 \%$ and $1 \%$ is $28.50 \mathrm{kgf} / \mathrm{mm}^{2}$ and $24.17 \mathrm{kgf} / \mathrm{mm}^{2}$, respectively.

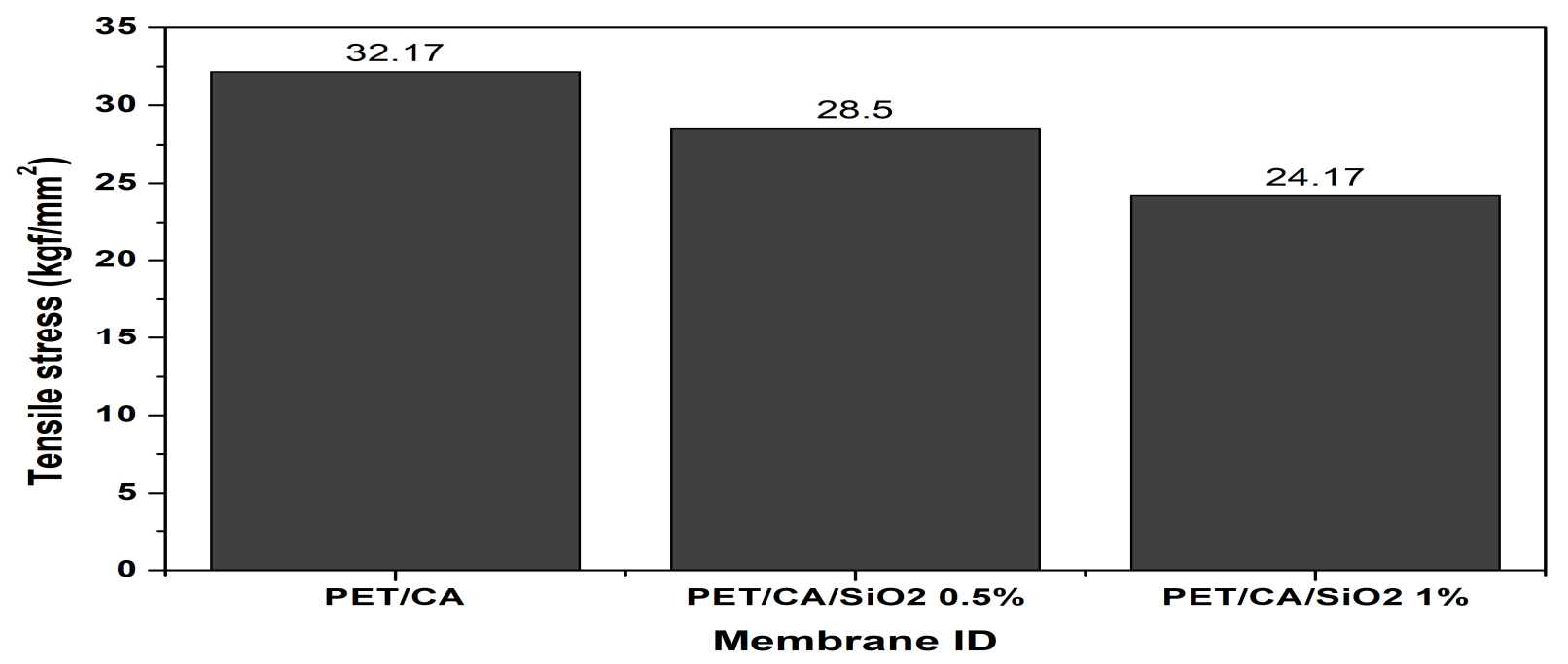

Fig.-8: The Tensile Strength of the Membrane with Various Silica Addition.

\section{CONCLUSION}

The abundant waste of plastic bottles can be managed by reusing the bottle to produce PET as the main polymer in membrane preparation. The addition of CA as a sub-polymer and silica as an additive completely covered the weakness of the PET membrane. The formed membrane has an improved hydrophilicity, stronger mechanical strength and enhanced pore properties. Silica has a great affinity towards the water which leads to the increased pure water flux for the silica-blended membranes.

\section{REFERENCES}

1. I. G. Wenten, Teknologi Membran: Prospek dan Tantangannya di Indonesia, 2016

2. N. Arahman, A. Fahrina, S. Amalia, R. Sunarya, S. Mulyati, F1000Res., 6, 1(2017), DOI: 10.12688/f1000research.11501.1

3. A. H. Bahremand, S. M. Mousavi, A. Ahmadpour, M. Taherian, Carbohydr. Polym., 173, 497(2017), DOI: $10.1016 /$ j.carbpol.2017.06.010

4. H. Webb, J. Arnott, R. Crawford, E. Ivanova, Polymers, 5, 1(2013),DOI: 10.3390/polym5010001

5. S. Rajesh, Z. V. P. Murthy, Quím. Nova, 37, 653(2014), DOI: 10.5935/0100-4042.20140097

6. N. Kusumawati, P. Setiarso, S. Muslim, Rasayan J. Chem., 11, 1034(2018), DOI: 10.31788/RJC.2018.1133020

7. S. E. Cahyaningrum, N. Herdyastuti, A. Firdausa, D. Yanrita, Rasayan J. Chem., 10, 959(2017), DOI: $10.7324 /$ RJC.2017.1031635

8. I. Gustian, Asdim, E. Maryanti, Rasayan J. Chem., 9, 608(2016)

9. G. Li, J. Wang, D. Hou, Y. Bai, H. Liu, J. Environ. Sci., 45, 7(2016), DOI: 10.1016/j.jes.2015.11.025

10. A. El-Gendi, H. Abdallah, A. Amin, S. K. Amin, J. Mol. Struct., 1146, 14(2017), DOI: 10.1016/j.molstruc.2017.05.122

11. Z. Sun, and F. Chen, Int. J. Biol. Macromol., 91, 143(2016), DOI: 10.1016/j.ijbiomac.2016.05.072

12. J.-n. Shen, H.-m. Ruan, L.-g. Wu, C.-j. Gao, Chem. Eng. J., 168, 1272(2011), DOI: 10.1016/j.cej.2011.02.039

13. J. Lin, W. Ye, K. Zhong, J. Shen, N. Jullok, A. Sotto, B. Van der Bruggen, Chem. Eng. Process., 107, 194(2016), DOI: 10.1016/j.cep.2015.03.011

14. S.-Y. Wang, L.-F. Fang, L. Cheng, S. I. Jeon, N. Kato, H. Matsuyama, J. Membr. Sci., 549, 101(2017), DOI: 10.1016/j.memsci.2017.11.074

15. T. Riaz, A. Ahmad, S. Saleemi, M. Adrees, F. Jamshed, A. M. Hai, T. Jamil, Carbohydr. Polym., 153, 582(2016), DOI: 10.1016/j.carbpol.2016.08.011 
RASĀYAN J. Chem.

Vol. 11 | No. 4 |1609 - 1617| October - December | 2018

16. H. Yu, X. Zhang, Y. Zhang, J. Liu, H. Zhang, Desalination, 326, 69(2013), DOI: 10.1016/j.desal.2013.07.018

17. Q. Zhang, J. Jiang, F. Gao, G. Zhang, X. Zhan, F. Chen, Chem. Eng. J., 321, 412(2017), DOI: 10.1016/j.cej.2017.03.105

18. S. Feng, G. Yu, X. Cai, M. Eulade, H. Lin, J. Chen, Y. Liu, B.-Q. Liao, Bioresour. Technol., 244, 560(2017), DOI: 10.1016/j.biortech.2017.07.160

19. S. Mulyati, M. A. Armando, H. Mawardi, F. A. Azmi, W. P. Pratiwi, A. Fadzlina, R. Akbar, Syawaliah, IOP Confer. Series: Materials Science and Engineering, 334, 012040(2018), DOI: 10.1088/1757-899X/334/1/012040

20. S. H. Woo, B. R. Min, J. S. Lee, Sep. Purif. Technol., 187, 274(2017), DOI: 10.1016/j.seppur.2017.06.030

21. Y. He, L. Xu, X. Feng, Y. Zhao, L. Chen, J. Membr. Sci., 539, 421(2017), DOI: 10.1016/j.memsci.2017.06.028

22. H. P. Ngang, A. L. Ahmad, S. C. Low, B. S. Ooi, IOP Confer. Series: Materials Science and Engineering, 206, 012083(2017), DOI: 10.1088/1757-899X/206/1/012083

23. X. Zhao, H. Xuan, Y. Chen, C. He, J. Membr. Sci., 494, 48(2015), DOI: 10.1016/j.memsci.2015.07.052

[RJC-4047/2018] 